\title{
Research of Stability and Nonlinear Vibrations by R-Functions Method
}

\author{
Jan Awrejcewicz, Lidiya Kurpa, and Olga Mazur
}

\section{Introduction}

The most modern constructions used in building, aerospace and other fields are modulated by plate and shell structures. Vibration research of plates loaded by compressive pulsating force has received particular interest, since in such system dynamic instability may occur, due to certain combinations of parameters of load and eigenfrequency. Given problem was reviewed by Sahu and Datta [1]. Dynamic instability was investigated by Bolotin [2], Hutt and Salam [3] and many others. Investigation of nonlinear parametric vibrations was carried out in references [2, 4-6], and others. However, in the mentioned works dynamic behavior of rectangular plates with some classical types of boundary conditions has been studied. On the other hand, many components of modern engineering constructions have different shape, and in particular they may be with cutouts.

In the present work stability and nonlinear vibrations of plates with central cutout are investigated. R- functions method (RFM) [7] and variational one are applied to get over the mathematical difficulties related to complex form of plates. The main idea of offered approach is focused on reducing the von Kármán equations governing dynamics of isotropic plates to an ordinary differential equation regarding time by the Bubnov-Galerkin method. Coefficients of this equation are found by R-functions theory.

Instability regions and nonlinear response characteristics are determined. The influence of size of cutout [8,9], boundary conditions and parameters of load [11] on investigated characteristics is studied.

\footnotetext{
J. Awrejcewicz

Department of Automatics and Biomechanics, Technical University of Lodz, Poland, e-mail: awrejcew@p.lodz.pl

L. Kurpa and O. Mazur

Department of Applied Mathematics, NTU "Kharkov Politechnical Institute”, Ukraine, e-mail: Kurpa@kpi.kharkov.ua., OlgaMazur@ukr.net
} 


\section{Formulation}

The isotropic plate with constant thickness $h$ is subjected to an uniformly distributed in-plane load of the form

$$
\mathrm{p}=\mathrm{p}_{0}+\mathrm{p}_{\mathrm{t}} \cos \theta \mathrm{t},
$$

where $\mathrm{p}_{0}$ is the static component of $\mathrm{p}(\mathrm{t}), \mathrm{p}_{\mathrm{t}}$ is the amplitude of the dynamic component of $p(t)$, and $\theta$ is the frequency of excitation.

The governing equations of nonlinear dynamics of plate have the form [6]

$$
\begin{aligned}
& \frac{\partial N_{x}}{\partial x}+\frac{\partial T}{\partial y}=0 \\
& \frac{\partial N_{y}}{\partial y}+\frac{\partial T}{\partial x}=0 \\
& D \nabla^{4} w=\left(\frac{\partial^{2} w}{\partial x^{2}} N_{x}+2 \frac{\partial^{2} w}{\partial x \partial y} T+\frac{\partial^{2} w}{\partial y^{2}} N_{y}\right)-\rho h \frac{\partial^{2} w}{\partial t^{2}}
\end{aligned}
$$

In Eqs. (2), (3) $\mathrm{N}_{\mathrm{x}}, \mathrm{N}_{\mathrm{y}}, \mathrm{T}$ are membrane stress resultants [6], $\mathrm{u}, \mathrm{v}, \mathrm{w}$ are the displacements regarding $x, y$ and $z$ directions, respectively; $E$ is elasticity modulus, $\mu$ is Possion's ratio, $\rho$ is density of plate, $D=\mathrm{Eh}^{3} /\left(12\left(1-\mu^{2}\right)\right)$ is flexural rigidity.

Different types of the boundary conditions for deflection $w$ are considered:

1. Clamped plate (C)

$$
\mathrm{w}=0, \frac{\partial \mathrm{w}}{\partial \mathrm{n}}=0,(\mathrm{x}, \mathrm{y}) \in \partial \Omega
$$

2. Simply supported plate (SS)

$$
\mathbf{w}=0, \mathbf{M}_{\mathbf{n}}=0,(\mathrm{x}, \mathrm{y}) \in \partial \Omega
$$

3. Mixed boundary conditions (type $1-\mathrm{C}-\mathrm{SS}$ )

$$
\begin{aligned}
& w=0, \frac{\partial w}{\partial \mathbf{n}}=0,(x, y) \in \partial \Omega_{1}, \\
& w=0, \mathbf{M}_{n}=0,(x, y) \in \partial \Omega_{2} \\
& \partial \Omega_{1} \cup \partial \Omega_{2}=\partial \Omega ;
\end{aligned}
$$

4. Mixed boundary conditions (type $2-$ SS-F, $\ll F \gg-$ free edge)

$$
\begin{aligned}
& w=0, M_{n}=0,(x, y) \in \partial \Omega_{1} \\
& \mathbf{M}_{n}=0, Q_{n}=0,(x, y) \in \partial \Omega_{2} \\
& \partial \Omega_{1} \cup \partial \Omega_{2}=\partial \Omega
\end{aligned}
$$

Displacements $u$ and $v$ have to satisfy the following conditions: Namely, and on loaded part of the boundary

$$
\mathrm{N}_{\mathrm{n}}=-\mathrm{p}, \mathrm{N}_{\tau}=\mathbf{0}
$$


on unloaded part of the boundary

$$
\mathrm{N}_{\mathrm{n}}=0, \mathrm{~N}_{\tau}=0 .
$$

In Eqs. (4)-(9) $M_{n}$ is bending moment, $Q_{n}$ is transverse force, $N_{n}, N_{\tau}$ are normal and tangent forces [6], and $n, \tau$ are normal and tangent to domain boundary $\partial \Omega$.

The initial conditions have the following form

$$
\mathrm{w} / \mathrm{t}=0=\mathrm{w}_{0}, \mathrm{w}_{/ \mathrm{t}=0}^{\prime}=0 .
$$

Later, we use nondimensional form of equations. Relations between dimensional and nondimensional values are defined as follows

$$
\begin{aligned}
\overline{\mathrm{x}} & =\frac{\mathrm{x}}{\mathrm{a}}, \overline{\mathrm{y}}=\frac{\mathrm{y}}{\mathrm{a}}, \overline{\mathrm{w}}=\frac{\mathrm{w}}{\mathrm{h}}, \overline{\mathrm{u}}=\frac{\mathrm{ua}}{\mathrm{h}^{2}}, \overline{\mathrm{v}}=\frac{\mathrm{va}}{\mathrm{h}^{2}}, \\
\overline{\mathrm{N}_{\mathrm{x}}} & =\frac{\mathrm{N}_{\mathrm{x}} \mathrm{a}^{2}}{\mathrm{Eh}^{3}}, \overline{\mathrm{N}_{\mathrm{x}}}=\frac{\mathrm{N}_{\mathrm{x}} \mathrm{a}^{2}}{\mathrm{Eh}^{3}}, \overline{\mathrm{T}}=\frac{\mathrm{Ta}^{2}}{\mathrm{Eh}^{3}}, \overline{\mathrm{N}_{\mathrm{n}}}=\frac{\mathrm{N}_{\mathrm{n}} \mathrm{a}^{2}}{\mathrm{Eh}^{3}}, \overline{\mathrm{N}_{\tau}}=\frac{\mathrm{N}_{\tau} \mathrm{a}^{2}}{\mathrm{Eh}^{3}} \\
\overline{\mathrm{p}} & =\frac{\mathrm{pa}^{2}}{\mathrm{Eh}^{3}}, \overline{\mathrm{t}}=\frac{\mathrm{h}}{\mathrm{a}^{2}} \sqrt{\frac{\mathrm{E}}{\rho} \mathrm{t}}, \bar{\theta}=\frac{\mathrm{a}^{2}}{\mathrm{~h}} \sqrt{\frac{\rho}{\mathrm{E}}} \theta, \overline{\omega_{\mathrm{L}}}=\frac{\mathrm{a}^{2}}{\mathrm{~h}} \sqrt{\frac{\rho}{E}} \omega_{\mathrm{L}} .
\end{aligned}
$$

where $\omega_{L}$ denotes linear frequency. In what follows, bars over nondimensional values are omitted.

Substituting expressions for $\mathbf{N}_{\mathrm{x}}, \mathrm{N}_{\mathrm{y}}, \mathrm{T}$ into Eqs. (2), (3) and taking into account Eq. (10), system Eqs. (2), (3) in displacements u, v, w may be presented in the following form

$$
\begin{gathered}
A \bar{U}=\overline{N L}(w), \\
\frac{1}{12\left(1-\mu^{2}\right)} \nabla^{4} w=\frac{\partial^{2} w}{\partial x^{2}} N_{x}(u, v, w)+ \\
+2 \frac{\partial^{2} w}{\partial x \partial y} T(u, v, w)+\frac{\partial^{2} w}{\partial y^{2}} N_{y}(u, v, w)-\frac{\partial^{2} w}{\partial t^{2}}
\end{gathered}
$$

where the vector $\overline{\mathrm{U}}$ and nonlinear operator $\overline{\mathrm{N}}(w)$ have the following form

$$
\begin{array}{r}
\bar{U}=\left(\begin{array}{l}
u \\
v
\end{array}\right), A=\left(\begin{array}{cc}
\frac{\partial^{2}}{\partial x^{2}}+\frac{1-\mu}{2} \frac{\partial^{2}}{\partial y^{2}} & \frac{1+\mu}{2} \frac{\partial^{2}}{\partial x \partial y} \\
\frac{1+\mu}{2} \frac{\partial^{2}}{\partial x \partial y} & \frac{\partial^{2}}{\partial y^{2}}+\frac{1-\mu}{2} \frac{\partial^{2}}{\partial x^{2}}
\end{array}\right), \\
\overline{N l}(w)=-\left(\begin{array}{l}
\frac{\partial w}{\partial x} \frac{\partial^{2} w}{\partial x^{2}}+\frac{1+\mu}{2} \frac{\partial w}{\partial y} \frac{\partial^{2} w}{\partial x \partial y}+\frac{1-\mu}{2} \frac{\partial w}{\partial x} \frac{\partial^{2} w}{\partial y^{2}} \\
\frac{\partial w}{\partial y} \frac{\partial^{2} w}{\partial y^{2}}+\frac{1+\mu}{2} \frac{\partial w}{\partial x} \frac{\partial^{2} w}{\partial x \partial y}+\frac{1-\mu}{2} \frac{\partial w}{\partial y} \frac{\partial^{2} w}{\partial x^{2}}
\end{array}\right) .
\end{array}
$$




\section{Method of Solving}

Supposing that a plate is in the inhomogeneous subcriticality state, then at the first step of the proposed method the related problem of elasticity theory have to be solved:

$$
\mathrm{A} \overline{\mathrm{U}}_{1}=0
$$

with the associated boundary conditions on loaded part of the boundary

$$
\mathrm{N}_{\mathrm{n}}^{\mathrm{L}}\left(\mathrm{u}_{1}, \mathrm{v}_{1}\right)=-1, \mathrm{~N}_{\tau}^{\mathrm{L}}\left(\mathrm{u}_{1}, \mathrm{v}_{1}\right)=0
$$

and on unloaded part of boundary

$$
\mathrm{N}_{\mathbf{n}}^{\mathrm{L}}\left(\mathrm{u}_{1}, \mathrm{v}_{\mathbf{1}}\right)=0, \mathrm{~N}_{\mathfrak{\tau}}^{\mathrm{L}}\left(\mathrm{u}_{1}, \mathrm{v}_{1}\right)=0,
$$

where $N_{n}^{L}, N_{\tau}^{L}$ are normal and shear linear forces (linear part of $N_{n}, N_{\tau}$ ). The problem Eqs. (13)-(15) are solved by variational Ritz's method. The corresponding functional has the following form

$$
\begin{aligned}
\mathrm{I}_{1}\left(\overline{\mathbf{U}}_{1}\right)= & \iint_{\Omega}\left[\left(\frac{\partial \mathrm{u}_{1}}{\partial \mathrm{x}}\right)^{2}+\left(\frac{\partial \mathrm{v}_{1}}{\partial \mathrm{y}}\right)^{2}+\frac{1-\mu}{2}\left(\frac{\partial \mathrm{u}_{1}}{\partial \mathrm{y}}+\frac{\partial \mathrm{v}_{1}}{\partial \mathrm{x}}\right)^{2}+2 \mu \frac{\partial \mathrm{u}_{1}}{\partial \mathrm{x}} \frac{\partial \mathrm{v}_{1}}{\partial \mathrm{y}}\right] d \Omega+ \\
& +2\left(1-\mu^{2}\right) \int_{\partial \Omega}\left(\mathrm{u}_{1} 1+\mathrm{v}_{1} \mathrm{~m}\right) \mathrm{d} \partial \Omega
\end{aligned}
$$

where $1, m$ are directional cosines of normal $n$. Construction of system of the basic functions is carried out using the R-functions theory [7].

Our further investigation is reduced to linear vibration problem for the unloaded plate. To find the natural frequencies and related modes, Ritz's method and Rfunctions theory are used. The functional regarding this problem is constructed in the following form

$$
\begin{aligned}
\mathrm{I}_{2}(\mathrm{w})= & \iint_{\Omega}\left((\Delta \mathrm{w})^{2}-2(1-\mu)\left(\frac{\partial^{2} \mathrm{w}}{\partial \mathrm{x}^{2}} \frac{\partial^{2} \mathrm{w}}{\partial \mathrm{y}^{2}}-\left(\frac{\partial^{2} \mathrm{w}}{\partial \mathrm{x} \partial \mathrm{y}}\right)^{2}\right)\right. \\
& \left.-12\left(1-\mu^{2}\right) w_{\mathrm{L}}^{2} \mathrm{w}^{2}\right) \mathrm{d} \Omega .
\end{aligned}
$$

A solution to nonlinear system of Eqs. (11)-(12) is being sought for in the following form

$$
\begin{aligned}
\mathrm{w}(\mathrm{x}, \mathrm{y}, \mathrm{t}) & =\mathrm{f}(\mathrm{t}) \mathrm{w}_{1}(\mathrm{x}, \mathrm{y}), \\
\mathrm{u}(\mathrm{x}, \mathrm{y}, \mathrm{t}) & =\left(\mathrm{p}_{\mathrm{0}}+\mathrm{p}_{\mathrm{t}} \cdot \cos \theta \mathrm{t}\right) \mathrm{u}_{\mathrm{l}}(\mathrm{x}, \mathrm{y})+\mathrm{f}^{2}(\mathrm{t}) \cdot \mathrm{u}_{2}(\mathrm{x}, \mathrm{y}), \\
\mathrm{v}(\mathrm{x}, \mathrm{y}, \mathrm{t}) & =\left(\mathrm{p}_{0}+\mathrm{p}_{\mathrm{t}} \cdot \cos \theta \mathrm{t}\right) \mathrm{v}_{\mathrm{l}}(\mathrm{x}, \mathrm{y})+\mathrm{f}^{2}(\mathrm{t}) \cdot \mathrm{v}_{2}(\mathrm{x}, \mathrm{y}) .
\end{aligned}
$$


In the above functions $u_{1}(x, y), v_{1}(x, y), w_{1}(x, y)$ (eigenfunction, which corresponds to main frequency) are known functions, whereas functions $u_{2}(x, y), v_{2}(x, y)$ are found by solving inhomogeneous linear system of differential equations of the form

$$
\mathrm{A} \overline{\mathrm{U}}_{2}=\overline{\mathbf{N}} \mathbf{l}\left(\mathbf{w}_{1}\right),
$$

which simulates the plane elastic problem. Right hand-side of Eq. (17) can be considered as a fictitious force. Equation (17) is supplemented with the following boundary conditions

$$
\mathrm{N}_{\mathbf{n}}\left(\mathbf{u}_{2}, \mathbf{v}_{2}\right)=0, \mathrm{~N}_{\tau}\left(\mathrm{u}_{2}, \mathbf{v}_{2}\right)=0 .
$$

In order to solve the problem governed by Eqs. (17), (18) in the case of plates with complex form, the Ritz's method in combination with R-functions theory is applied. The functional used to solve the problem has the following form

$$
\begin{aligned}
\mathrm{I}_{3}\left(\overline{\mathrm{U}}_{2}\right)= & \iint_{\Omega}\left[\left(\frac{\partial \mathrm{u}_{2}}{\partial \mathrm{x}}\right)^{2}+\left(\frac{\partial \mathrm{v}_{2}}{\partial \mathrm{y}}\right)^{2}+\frac{1-\mu}{2}\left(\frac{\partial \mathrm{u}_{2}}{\partial \mathrm{y}}+\frac{\partial \mathrm{v}_{2}}{\partial \mathrm{x}}\right)^{2}+2 \mu \frac{\partial \mathrm{u}_{2}}{\partial \mathrm{x}} \frac{\partial \mathrm{v}_{2}}{\partial \mathrm{y}}\right] \mathrm{d} \Omega- \\
& \left.-2\left(\overline{\mathrm{N} l}\left(\mathrm{w}_{1}\right), \overline{\mathrm{U}}_{2}\right)\right] \mathrm{d} \Omega .
\end{aligned}
$$

It is easy to see, the displacements $u, v, w$ represented by Eqs. (16) satisfy the system Eqs. (11), (12) with the corresponding boundary conditions.

Substituting Eq. (16) into Eq. (12) and applying the Bubnov-Galerkin method the following nonlinear differential equation is obtained.

$$
f^{\prime \prime}(t)+\omega_{L}^{2}\left(1-\alpha p_{0}-\alpha p_{t} \cos \theta t\right) f(t)+\beta f^{3}(t)=0,
$$

where the coefficients $\alpha, \beta$ are defined as follows

$$
\begin{aligned}
& \alpha=\frac{1}{\omega_{\mathrm{L}}^{2}\left\|\mathrm{w}_{1}\right\|^{2}} \iint_{\Omega}\left(\frac{\partial^{2} \mathrm{w}_{1}}{\partial \mathrm{x}^{2}} \mathrm{~N}_{\mathrm{x}}^{\mathrm{L}}\left(\mathrm{u}_{1}, \mathrm{v}_{1}\right)+2 \frac{\partial^{2} \mathrm{w}_{1}}{\partial \mathrm{x} \partial \mathrm{y}} \mathrm{T}^{\mathrm{L}}\left(\mathrm{u}_{1}, \mathrm{v}_{1}\right)+\right. \\
& \left.+\frac{\partial^{2} \mathrm{w}_{1}}{\partial \mathrm{y}^{2}} \mathrm{~N}_{\mathrm{y}}^{\mathrm{L}}\left(\mathrm{u}_{1}, \mathrm{v}_{1}\right)\right) \mathrm{w}_{1} \mathrm{~d} \Omega \\
& \beta=-\frac{1}{\left\|w_{1}\right\|^{2}} \iint_{\Omega}\left(\frac{\partial^{2} w_{1}}{\partial x^{2}} N_{x}\left(u_{2}, \mathbf{v}_{2}, w_{1}\right)+2 \frac{\partial^{2} w_{1}}{\partial x \partial y} \mathbf{T}\left(u_{2}, \mathbf{v}_{2}, w_{1}\right)+\right. \\
& \left.+\frac{\partial^{2} \mathrm{w}_{1}}{\partial \mathrm{y}^{2}} \mathrm{~N}_{\mathrm{y}}\left(\mathrm{u}_{2}, \mathrm{v}_{2}, \mathrm{w}_{1}\right)\right) \mathrm{w}_{1} \mathrm{~d} \Omega \text {. }
\end{aligned}
$$

In the above $N_{x}^{L}, N_{y}^{L}, T^{L}$ are linear membrane stress resultants (linear part of $N_{x}, N_{y}$, T).

Equation (19) can be cast into the following form

$$
\mathbf{f}^{\prime \prime}(\mathrm{t})+\Omega^{2}(1-2 \mathrm{k} \cdot \cos (\theta t)) f(t)+\beta \mathbf{f}^{3}(t)=0,
$$


where $\Omega=\omega_{L}\left(1-p_{0} \alpha\right)^{1 / 2}$ is vibration frequency of a plate loaded by static component $\mathrm{p}_{0}$, and $\mathrm{k}=\mathrm{p}_{\mathrm{t}} \alpha /\left(2-2 \mathrm{p}_{0} \alpha\right)$ is excitation coefficient.

\section{Stability Analysis}

To determine instability regions, the Bolotin's method [2] is used. If one takes in (21) the coefficient $\beta=0$, then the Mathieu equation, governing linear plate parametric vibrations plate is obtained of the form

$$
\mathrm{f}^{\prime \prime}(\mathrm{t})+\Omega^{2}(1-2 \mathrm{k} \cdot \cos (\theta \mathrm{t})) \mathbf{f}(\mathrm{t})=0 .
$$

It is well known that the solutions of the Eq. (22) can be bounded or unbounded. The boundaries between stable and unstable solutions are formed by periodic solutions with period $T$ and $2 T$, where $T=2 \pi / \theta$. Two solutions of the same period confine regions of instability (in the vicinity of $\theta=2 \Omega / r, r=1,2,3, \ldots$ ), two solutions with different periods confine the regions of stability. Equations of curves, bounding regions of stability and instability are known. The first region of instability is defines by the curves

$$
\theta_{1}=2 \Omega \sqrt{1-k}, \theta_{2}=2 \Omega \sqrt{1+k} .
$$

\section{R-Functions Method}

R-functions theory is used to construct the system of basic functions for solving problems governed by Eqs. (13)-(15), Eqs. (17), (18), and the problem of linear vibrations of unloaded plate. According to the RFM, to create structures of solutions, it is necessary to construct the equation of the domain boundary. Method of these equations construction is described in [7]. Equation of boundary $\omega(x, y)$, constructed in such a way, satisfy the following conditions

$$
\omega(x, y)=0, \omega(x, y)>0, \frac{\partial \omega}{\partial \mathrm{n}}=-1,(x, y) \in \partial \Omega .
$$

Structures of solutions, which satisfy only principal boundary conditions can be constructed in the following way:

1. For the boundary conditions defined by (4), (8), (9):

$$
\mathrm{w}_{1}=\omega^{2} \mathrm{P}_{0}, \mathrm{u}_{\mathrm{i}}=\mathrm{P}_{\mathrm{i}}, \mathrm{v}_{\mathrm{i}}=\mathrm{P}_{\mathrm{i}+2}, \mathrm{i}=1 . .2 ;
$$

2. For the boundary conditions defined by (5), (8), (9):

$$
\mathrm{w}_{1}=\omega_{1} \mathrm{P}_{0}, \mathrm{u}_{\mathrm{i}}=\mathrm{P}_{\mathrm{i}}, \mathrm{v}_{\mathrm{i}}=\mathrm{P}_{\mathrm{i}+2}, \mathrm{i}=1 . .2 \text {. }
$$


3. For boundary conditions defined by (6), (8), (9):

$$
w_{1}=w_{1} \omega P_{0}, u_{i}=P_{i}, v_{i}=P_{i+2}, i=1 . .2 ;
$$

4. For boundary conditions defined by (7), (8), (9):

$$
w_{1}=w_{1} P_{0}, u_{i}=P_{i}, v_{i}=P_{i+2}, i=1 . .2 \text {. }
$$

In Eqs. (23) - (26) $\omega=0$ defines the equation of domain boundary, in Eq. (25) $w_{1}=$ 0 corresponds to equation of clamped part of the domain boundary, and in Eq. (26) $\omega_{1}=0$ is the equation of simply supported part of the boundary domain. Uncertain components $P_{i}, i=0, \ldots, 4$ are presented as decomposition in the series with a help of some complete system of functions. In this work the system of power polynomials is used.

\section{Numerical Results}

Numerical results presented in the work concern a plate with a central cutout (Fig. 1) subjected to load (23) for different boundary conditions. In this case the equation of domain boundary is constructed in the following way:

$$
\omega(x, y)=\left(f_{1} \wedge_{0} f_{2}\right) \wedge_{0}\left(\overline{f_{3}} \vee_{0} \overline{f_{4}}\right)
$$

The required R-operations, used in Eq. (27), are as follows

$$
x \wedge_{0} y=x+y-\sqrt{x^{2}+y^{2}}, x \vee_{0} y=x+y+\sqrt{x^{2}+y^{2}}, \bar{x}=-x .
$$

Functions $\mathrm{f}_{\mathrm{i}}, \mathrm{i}=1, \ldots, 4$ appeared in Eq. (27) are determined as follows

$$
\begin{aligned}
& \mathrm{f}_{1}=1 / \mathrm{a}\left((\mathrm{a} / 2)^{2}-\mathrm{x}^{2}\right), \mathrm{f}_{2}=1 / \mathrm{b}\left((\mathrm{b} / 2)^{2}-\mathrm{y}^{2}\right), \\
& \mathrm{f}_{3}=1 / \mathrm{c}\left((\mathrm{c} / 2)^{2}-\mathrm{x}^{2}\right), \mathrm{f}_{4}=1 / \mathrm{d}\left((\mathrm{d} / 2)^{2}-\mathrm{y}^{2}\right) .
\end{aligned}
$$

In order to taste the offered method, calculations of plate eigenfrequencies for different size of cutout are carried out. Boundary conditions SS-F (Fig. 2) are considered. These boundary conditions are associated with the structure of solution to Eq. (26). The obtained results are presented in Table 1.

The values of parameters used in our further analysis follow: $a / b=1, c=d$, $\mu=0.3$. In the present work only primary region of instability is considered.

Investigation of influence of boundary conditions (Fig. 2) on instability regions (Fig. 3) and fundamental frequency (Table 2) is carried out. Instability regions are presented for $\mathrm{p}_{0}=1, \mathrm{c} / \mathrm{a}=0.2$. The obtained results exhibit the following effect: for conditions SS-F instability domain is located lower then other ones and has a smaller area. Instability domains of plates with boundary conditions SS-SS, C-SS 


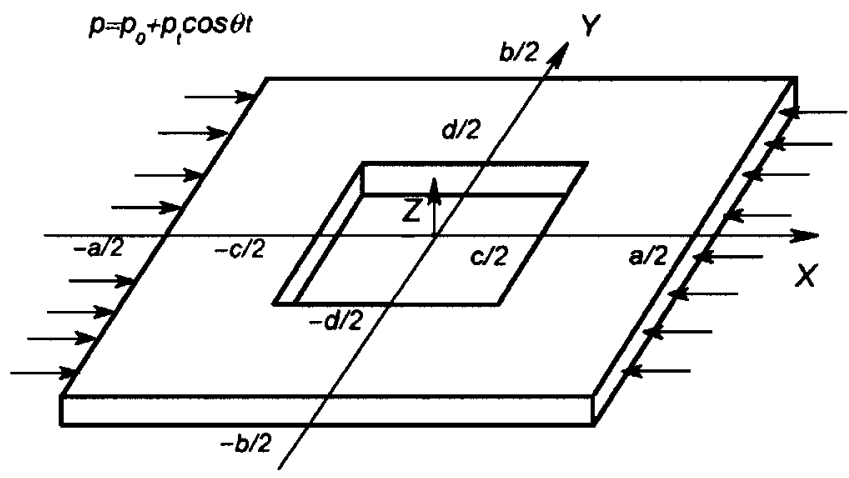

Fig. 1 The analyzed plate
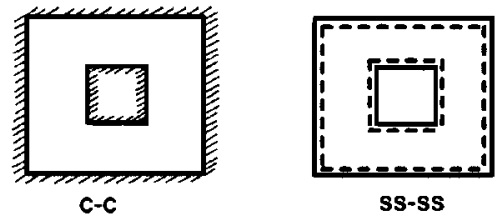

SS-SS
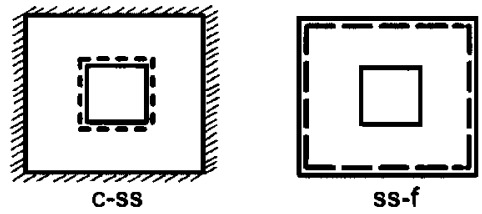

Fig. 2 Boundary conditions

Table 1 Comparison of non-dimensional fundamental frequencies $\lambda=\omega_{\mathrm{L}} \mathrm{a}^{2}(\rho \mathrm{h} / \mathrm{D})^{1 / 2}$ of a simply supported square plate with a free cutout

\begin{tabular}{lcccc}
\hline c/a & Present & {$[8]$} & {$[9]$} & {$[10]$} \\
\hline 0 & 19,742 & 19,734 & 19,739 & 19,740 \\
0.2 & 19,708 & 19,134 & 18,901 & 18,762 \\
0.4 & 21,108 & 20,739 & 20,556 & 20,785 \\
0.5 & 23,791 & 23,422 & 23,329 & 23,664 \\
0.6 & 28,719 & 28,307 & 28,491 & 28,844 \\
0.8 & 57,948 & 56,949 & 58,847 & 58,062 \\
\hline
\end{tabular}

and $\mathrm{C}-\mathrm{C}$ correspond to a larger value of excitation frequency $\theta$ and occupy a larger area.

The effect of the static load factor on instability region is investigated for a plate satisfying boundary conditions SS-F (Fig. 3). Static load factor takes the values $\mathrm{p}_{0}=0.5,1,1.5(\mathrm{c} / \mathrm{a}=0.2)$. Owing to increase of static component, instability regions remove to lower value of the excitation frequencies.

For a given plate, effect of cutout size is studied for different values of ratio $\mathrm{c} / \mathrm{a}\left(0 \leq \mathrm{c} / \mathrm{a} \leq 0.4, \mathrm{SS}-\mathrm{F}, \mathrm{p}_{0}=1\right)$. Instability region (see Fig. 4) is shifted to the lower value of excitation frequencies up to $\mathrm{c} / \mathrm{a}=0.28$. Instability regions tend to a larger value of excitation frequencies from $\mathrm{c} / \mathrm{a}=0.28$ to $\mathrm{c} / \mathrm{a}=0.4$ (for $\mathrm{p}_{0}=2$ behavior of the system is similar). 

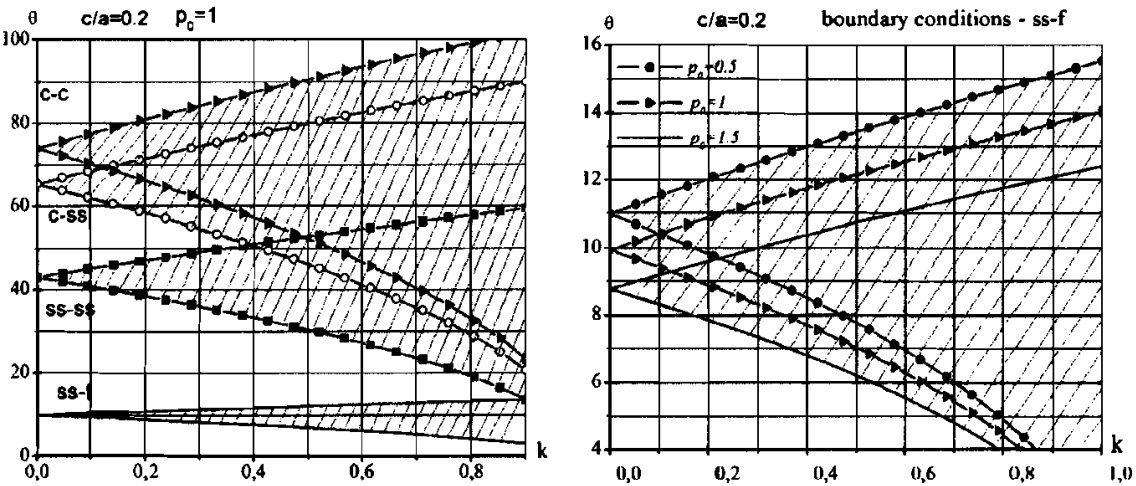

Fig. 3 Effect of boundary conditions and static component on instability regions

Table 2 Non-dimensional fundamental frequencies $\lambda=\omega_{L} a^{2}(\rho \mathrm{h} / \mathrm{D})^{1 / 2}$ of a square plate with a cutout for different boundary conditions

\begin{tabular}{lrrr}
\hline c/a & C-C & SS-SS & C-SS \\
\hline 0 & 123.649 & 73.249 & 109.307 \\
0.2 & 230.334 & 125.148 & 188.225 \\
0.4 & 315.753 & 167.648 & 255.669 \\
0.5 & 511.139 & 260.824 & 397.456 \\
0.6 & 1833.052 & 994.522 & 153.941 \\
\hline
\end{tabular}
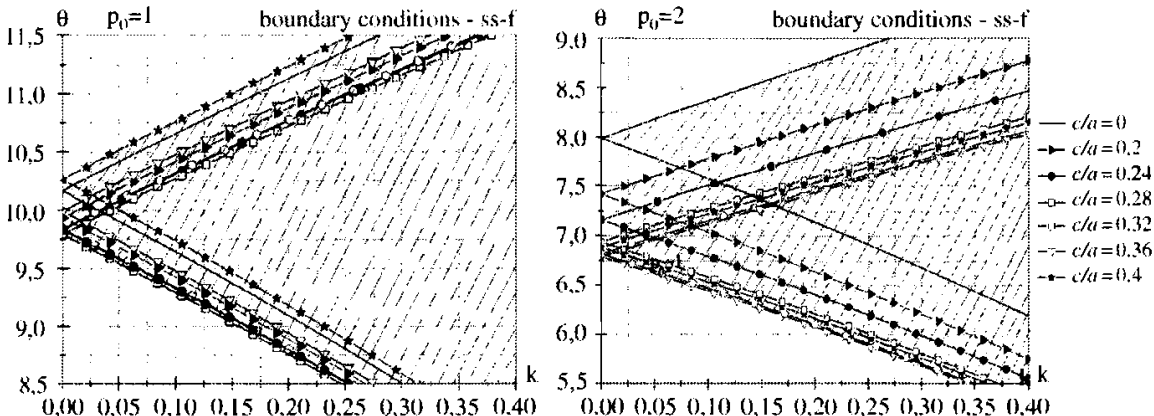

Fig. 4 Effect of size of cutout on instability regions

Next, the dynamic nonlinear response for chosen values of load parameters $\mathrm{p}_{0}=\mathrm{p}_{\mathrm{t}}=1$ with initial amplitudes $\mathrm{w}_{0} / \mathrm{h}=0.0001$ and $\mathrm{t} \in[0.500]$ is studied (see Fig.4). It should be emphasized, that instability region predicated by the linear theory almost coincides with results obtained by nonlinear analysis. It can also be seen that the amplitudes are comparable with initial conditionsoutside of instability region. In a critical zone the amplitude values increase. The influence of the size of cutout on response curve are analyzed for different values of ratio $\mathrm{c} / \mathrm{a}\left(0 \leq \mathrm{c} / \mathrm{a} \leq 0.5, \mathrm{SS}-\mathrm{F}, \mathrm{p}_{0}=\mathrm{p}_{\mathrm{t}}=1\right)$ (Fig. 5). The extension of cutout leads to 


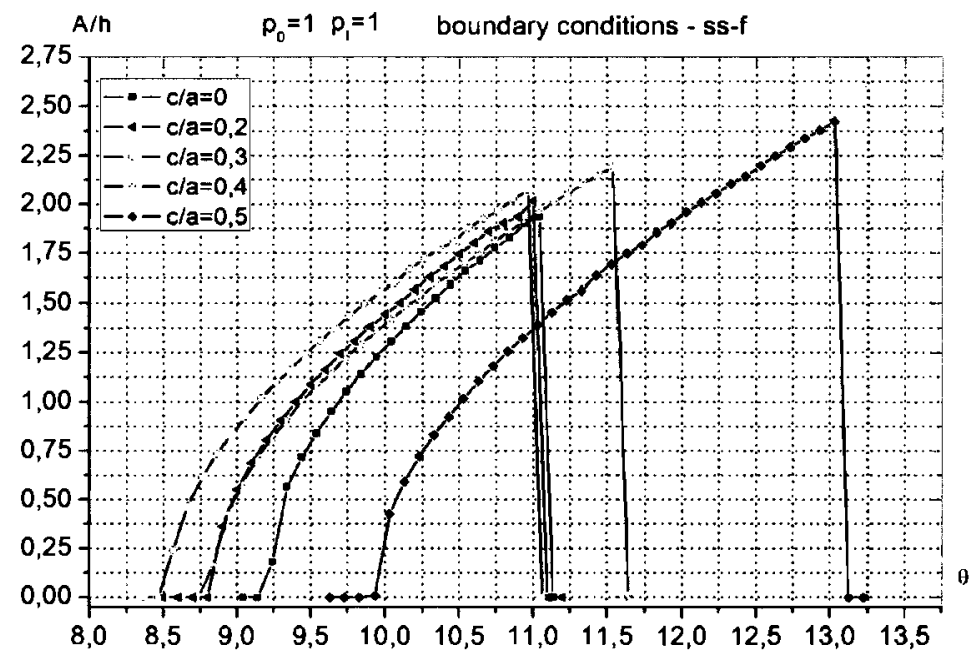

Fig. 5 Non-dimensional amplitudes for different size of cutout
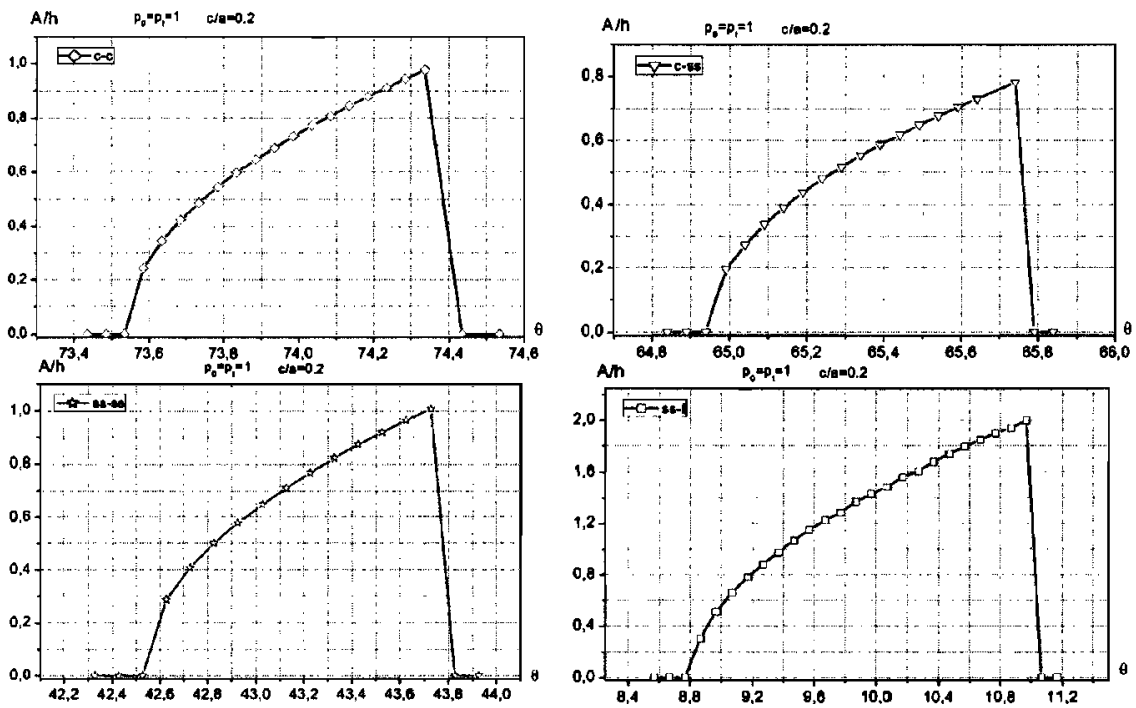

Fig. 6 Non-dimensional amplitudes for different types of boundary conditions

increase of the vibration amplitudes and movement of response curves (zone of resonance are located between critical frequencies $\theta_{1}$ and $\theta_{2}$ ). The values of amplitudes for various boundary conditions (C-C, C-SS, SS-SS, SS-F, c/a $=0.2, \mathrm{p}_{0}=\mathrm{p}_{\mathrm{t}}=1$ ) are also studied (Fig. 6). The amplitude values for the last considered boundary conditions are essentially larger. 


\section{Conclusions}

The obtained results can be summarized as follows: instability regions are shifted into lower frequencies with increase of a static load component. Change of the cutout size yields movement of instability regions: first to lower frequencies, and then to higher frequencies. On the other hand, nonlinear vibration analysis of plates allows to note that the extension of cutout causes an increase of vibration amplitudes.

\section{References}

1. Sahu SK, Datta PK (2007) Research Advances in the dynamic stability behavior of plates and shells: 1987-2005. Part 1: Conservative system. Applied Mechanics Reviews 60, 65-75.

2. Bolotin VV (1956) The Dynamic Stability of Elastic Systems, Gos. Tech. Izdat., Moscow (in Russian).

3. Hutt JM, Salam AE (1971) Dynamic stability of plates by finite element. Journal of the Engineering Mechanics Division 97, 879-899.

4. Awrejcewicz J, Krys'ko AV (2003) Analysis of complex parametric vibrations of plates and shells using Bubnov-Galerkin approach. Applied Mechanics 73, 495-504.

5. Ganapathi M, Patel BP, Boise P, Touratier M (2000) Non-linear dynamic stability characteristics of elastic plates subjected to periodic in-plane load. International Journal of Non-linear Machanics 35, 467-480.

6. Volmir AS (1972) Nonlinear Dynamics of Plates and Shells, Nauka, Moscow (in Russian).

7. Rvachev VL, Kurpa LV (1987) R-functions in Problems of Theory of Plates, Naukova Dumka, Kiev (in Russian).

8. Sahu SK, Datta PK (2002) Dynamic stability of curved panels with cutouts. Journal of Sound and Vibration 251(4), 683-696.

9. Lee HP, Lim SP, Chow ST (1990) Prediction of natural frequencies of rectangular plates with rectangular cutouts. Computers and Structures 36, 861-869.

10. Lam KY, Hung KC (1990) Orthogonal polynomials and subsectioning method for vibration of plates. Computers and Structures 34(6), 827-834.

11. Mundkur G, Bhat RB, Neriya S (1994) Vibration of plates with cutouts using boundary characteristics orthogonal polynomial functions in the Rayleigh-Ritz method. Journal of Sound and Vibration 176, 136-144. 